\title{
Analysis of Bending Test Technique for Osteosynthesis Titanium Plate
}

\author{
Y.N. Loginov¹,2, S.l.Stepanov¹, A.I. Golodnov¹, and G.Z. Mukanov ${ }^{1}$ \\ ${ }^{1}$ Ural Federal University, 19 Mira Street, 620002, Ekaterinburg, Russia \\ ${ }^{2}$ M.N. Miheev Institute of Metal Physics of Ural Branch of Russian Academy of Sciences, $18 \mathrm{~S}$. \\ Kovalevskaya Street, Yekaterinburg, Russia, 620137
}

\section{Abstract}

Titanium and its alloys often take the role of material for manufacturing the implants for orthopedic use. The purpose of the study is to determine the parameters of bending test of an implantable titanium plate used for osteosynthesis. The method described in the ISO 9585-2011 was analyzed for testing metal plates for fixation of fractured bone fragments. A comparison of the test results for plates on a 4-point bending for two different standards and the results of experiments are reported. The attention is drawn to the possibility of weakening of titanium plates with fixation holes.

Corresponding Author:

S.I.Stepanov

s.i.stepanov@urfu.ru

Received: 25 February 2019

Accepted: 9 April 2019

Published: 15 April 2019

Publishing services provided by Knowledge E

(c) Y.N. Loginov et al. This article is distributed under the terms of the Creative Commons

Attribution License, which permits unrestricted use and redistribution provided that the original author and source are credited.

Selection and Peer-review under the responsibility of The Ural school-seminar of metal scientists-young researchers Conference Committee.
Keywords: 4-point bending test, plate for osteosynthesis, titanium implant, mechanical properties

\section{Introduction}

Titanium in the field of surgery is often utilized as a material for the manufacturing of implants for osteosynthesis [1, 2], including bone fixing plates [3]. The titanium implants have less toxicity effect than the constructions of chromium and cobalt alloys. Titanium alloys are characterized by the great anti-corrosion properties as well as good compatibility with body tissues [4]. In medicine, the osteosynthesis operation serves for the surgical fixation of fractured bone fragments with various mechanical structures that ensure the long-term elimination of the mobility. The fixation is performed using various types of bone anchored implants. The fixing plates for osteosynthesis can be subjected to significant loads. Therefore, the problems of maintaining their strength come to the fore [5]. It should be noted that plates for osteosynthesis can be made both of commercially pure titanium (cp-Ti) and of a titanium alloy Ti-6-4 depending on the demanded strength. However, a high ductility is needed in order to be able to bend them manually during a surgical operation [6].

In scientific studies, the fracture mechanisms of titanium implants are more often studied from the standpoint of structural analysis [7], with less attention being paid to 
the stress-strain analysis. A special method of testing of metal plates for fixation bone fragments is used in accordance with the ISO 9585:1990 [8].

The purpose of the study is to determine the parameters of 4-point bending test of an implantable titanium plate intended for the fixation of fractured bone.

\section{Material and Methods}

The 4-point bending test is applied for flat elongated in length samples or products, e.g. plates. Namely, the Russian standard GOST 9550-81 [9] describes the 4-point bend test according to a scheme shown in Fig. 1.

This figure demonstrates that two loading points characterized by F/2 forces are located at equal distances $L_{v} / 3$ from the supports. The bending moment increases from the points of support to the points of application force of $F / 2$ and remains constant between them.

(a)

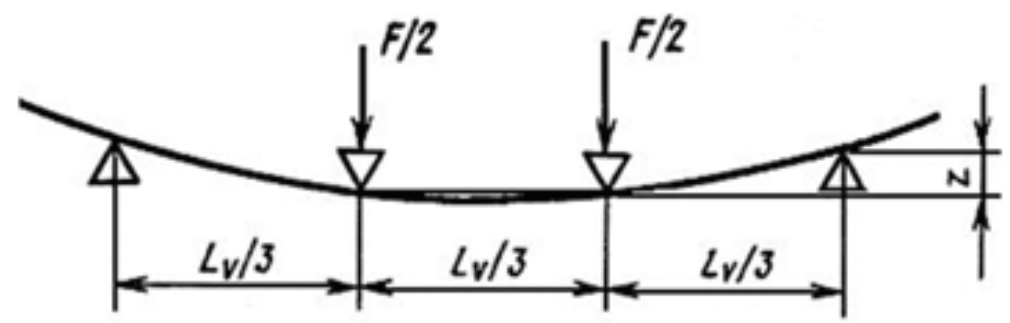

(b)

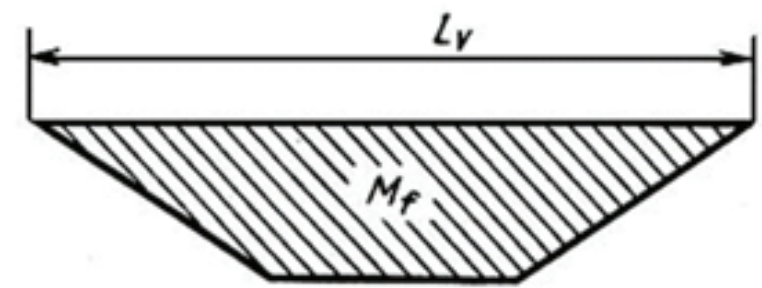

Figure 1: Loading scheme according to GOST 9550-81 (a) and bending moment diagram (b) for 4-point bending test (designations are described below).

The engineering strain of the extreme fibers of the plate is calculated according to the formula:

$$
\varepsilon=\frac{z h}{0,185 L_{v}^{2}} .
$$

Where $z$ - deflection of the plate; $h$ - gauge of the plate.

The forces $F_{1}$ and $F_{2}$ correspond to the $\varepsilon$ of extreme fibers which takes values of 0.1 and 0.3 according to the loading diagram. The elastic modulus for bending is estimated by the formula:

$$
E_{b}=\frac{0,185 L_{v}^{3}\left(F_{2}-F_{1}\right)}{b h^{3}\left(z_{2}-z_{1}\right)}
$$


Where the subscripts 1 and 2 correspond to the $\varepsilon$ values of 0.1 and $0.3 \% ; b$ - the width of the sample.

These calculations are accounted for the elastic properties of the material.

Note, that titanium osteosynthesis implants for external fixation can be made of different shapes depending on the purpose. The common thing for them is the shape of elongated plate with the holes for fastening to bone fragments in order to fix them (Fig. 2).

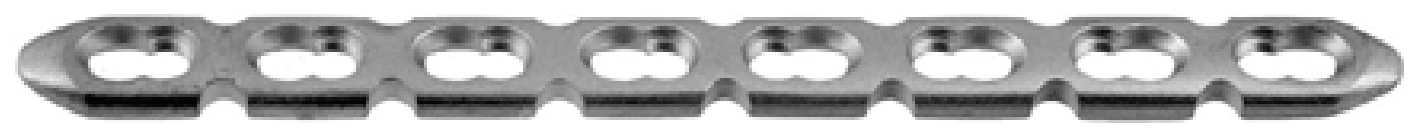

Figure 2: Titanium plate with a set fixation holes for osteosynthesis of fractures of the clavicle and fibula.

The holes result in local reduction of the cross section. In addition, the stresses are localized near the edges of the holes. Therefore, GOST 9550-81 requires clarification as the points of support may be opposite the holes, or, on the contrary, the holes may appear between the points of support, therefore the test results will not depend on the plate properties, but on the methods of its placement in the experiment.

In accordance with the ISO 9585:1990, the following test method is used for metal plates for fixation of bone fragments. The test plate (1) (Fig. 2) is placed between the upper pair (2) and the lower pair of cylindrical rollers (3).

The distance between the upper rollers is $\mathrm{k}$, and the distance between the upper and lower rollers is $h$. The force $F$ is applied to the upper pair of the rollers (2) through intermediate support (5). The plate (6) deflects upon loading in the longitudinal crosssection. Four rollers has cylindrical shape with the equal diameter in the range of 8-13 $\mathrm{mm}$ or a custom-tailored shape corresponding to the cross-section of the test plate. The assembly is loaded in the working opening press or the testing machine to measure a vertical displacement.

The difference between the test schemes of the two standards is the certain appointment of the distances between the supports. The force application points should be placed outside the fixation holes according to the ISO 9585. Thus, it is not possible to withstand equal distances of $L_{v} / 3$ as stated in the GOST 9550-81. Therefore, the requirement of the standard is to place the supports between the holes. Namely, Fig. 2 shows that there are two fixation holes between the upper supports.

The following characteristics are estimated: 


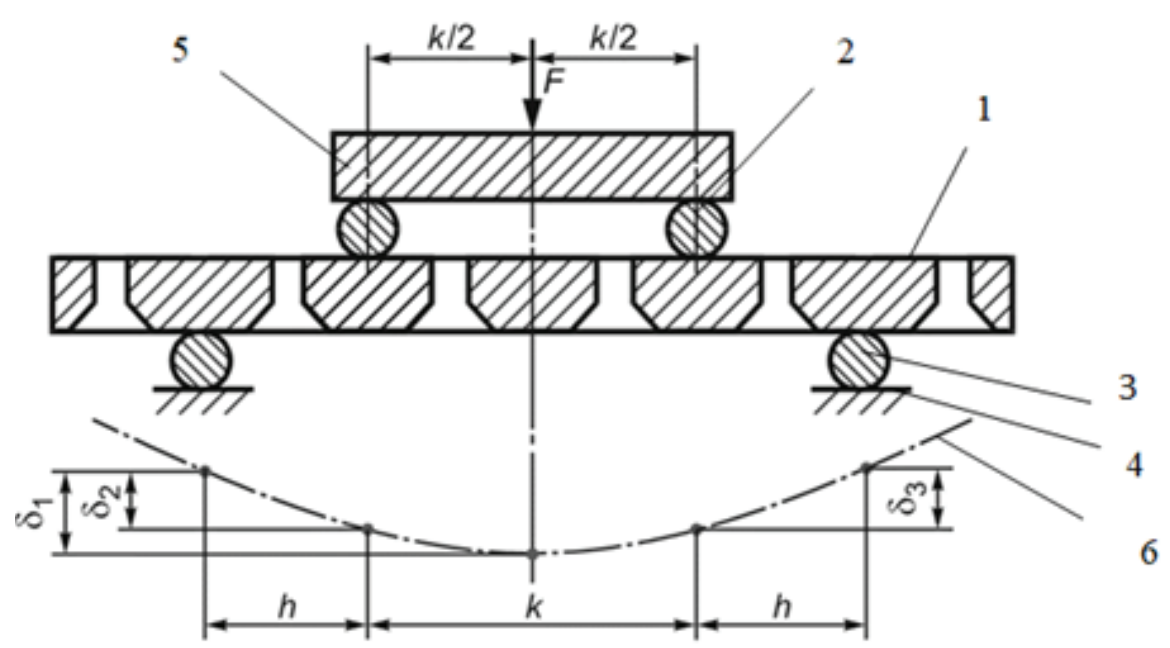

Figure 3: Loading scheme for 4-point test according to ISO 9585 (designations are described below).

1. Torque moment or moment of linear force which acts around the axis of plate, being the product of force $\mathrm{F}$ at a distance $\mathrm{h}[\mathrm{N} \cdot \mathrm{m}]$;

2. bending moment $\mathrm{M}_{b}$ : Moment acting about a centerline perpendicular to the long axis of the body and generally producing lateral deflection;

3. deflection $\delta_{1}, \delta_{2}$ or $\delta_{3}$ : Linear displacement due to bending, measured perpendicular to the original axis of the plate;

4. bending strength: Value of the bending moment at fracture, or at a specified proof point, whichever is the lower.

5. equivalent bending stiffness.

\section{Experimental Procedure}

The stress-strain curve was recorded during test. The bending strength was calculated according to the ISO 9585:1990 by the following formula:

$$
\sigma_{b}=0.5^{*} P^{*} h,
$$

Where $P$ is a relative bending load $[\mathrm{N}], h$ is the distance between the inner and outer rollers [m] (watch Fig. 2).

The load $\mathrm{P}$ is measured in the bend diagram and corresponds to the point of intersection with the line drawn parallel to the linear part of the diagram from the point corresponding to the deflection q, which is evaluated by the formula:

$$
q=0.02(2 h+k)
$$


From the bending diagram in Fig. $5, \mathrm{P}=1080 \mathrm{~N}, \sigma_{b}=8.1 \mathrm{~N}^{*} \mathrm{~m}$ are calculated for the test conditions of $\mathrm{h}=15 \mathrm{~mm}$ and $\mathrm{q}=1.2 * 10^{-3} \mathrm{~m}$.

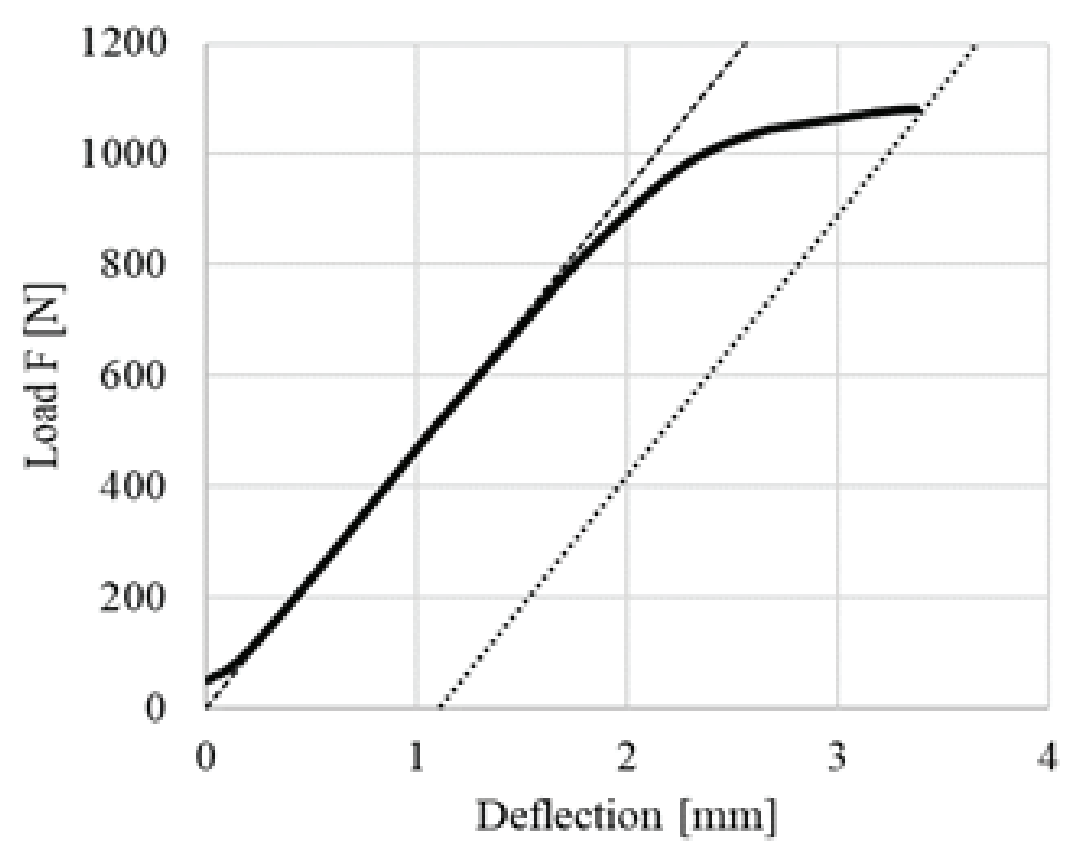

Figure 4: Stress-strain curve for 4-point bending of the osteosynthesis titanium plate.

Equivalent bending stiffness is evaluated from the slope tangent $\mathrm{S}=469 \mathrm{~N} / \mathrm{mm}$ of the elastic segment of the bending stress-strain curve. This magnitude takes into account the presence of holes in the plate according to the formula for the deflection measured on the centerline between the central holes:

$$
E=\frac{\left(4 h^{2}+12 h k+k^{2}\right) S h}{24}
$$

After substituting the required values, we obtain $E=2.11 \mathrm{~N}^{*} \mathrm{~m}^{2}$. For comparison, in [10], this magnitude was $1.40 \mathrm{~N}^{*} \mathrm{~m}^{2}$. The bending strength was equal to $9.53 \mathrm{~N}^{*} \mathrm{~m}$ for the similar plate against the $8.1 \mathrm{~N}^{*} \mathrm{~m}$ obtained in this experiment.

The experiments, described above and the calculations performed, relate to the estimation of the integral characteristics of the strength of the plates. A certain interest arises from the influence of the size of the holes and their location on the strength characteristics, since the plates are made with holes. This problem can be solved by simulation the problem using the finite element method. Thus, the stress will be much higher at the locations of the holes than in the immediate environment. Therefore, the problem of balancing the stresses will rise due to the strengthening of the zones adjacent to the holes. 
Note, that today the plate manufacturing is focused on the use of flat rolled products of titanium and its alloys. Herein, the semi-finished product for the manufacture of plates has a deliberately constant thickness. Thus, it can be assumed that it is possible to design plates of variable thickness. Particularly, the thickness must be increased in places of stress localization, which will provide a decrease in the level of local stresses. Therefore, an additive manufacturing can be an effective method of obtaining the plates for osteosynthesis. In contrast to the rolling method, it allows for tailoring the thickness by increasing it locally around the regions with the high equivalent stresses.

\section{Conclusions}

The comparison of two 4-point bending test methods for the osteosynthesis plates according to two different standards revealed that ISO 9585-2011 takes into account the presence of holes in the plates compared to GOST 9550-81. Due to the holes the distances between the bearing supports may not be equal. Thus, the bending properties cannot be compared for the same plates in these two types of the experiments. The investigation performed in accordance with the requirements of ISO 9585-2011 repots satisfactory convergence with the literature data.

\section{Acknowledgements}

We hereby acknowledge the support of the Ministry of Science and Education of the Russian Federation, in accordance to the decree of the Government of April 9, 2010, №218, project number 03.G25.31.0234.

The work was carried out using the laboratory equipment "Structural methods of analysis and properties of materials and nanomaterials" of the Center of Ural Federal University.

\section{References}

[1] V. Tuovinen, R. Suuronen, M. Teittinen, P. Nurmenniemi. Comparison of the stability of bioabsorbable and titanium osteosynthesis materials for rigid internal fixation in orthognathic surgery. A prospective randomized controlled study in 101 patients with 192 osteotomies, International Journal of Oral and Maxillofacial Surgery. (2010) 10591065. 
[2] Yu.N. Loginov, A.I. Golodnov, S.I. Stepanov, E.Yu. Kovalev, Determining the Young's modulus of a cellular titanium implant by FEM simulation, AIP Conference Proceedings. 1915, (2017) 030010.

[3] N. Theologie-Lygidakis, I. Iatrou, G. Eliades, S. Papanikolaou, A retrieval study on morphological and chemical changes of titanium osteosynthesis plates and adjacent tissues, Journal of Cranio-Maxillofacial Surgery. 35 (2007) 168-176.

[4] E.M. Ortrun Pohler, Unalloyed titanium for implants in bone surgery, Injury. 31 (2000) 7-13.

[5] W.J. Metsemakers, T. Schmid, S.Zeiter, M. Ernst, I. Keller, N. Cosmelli, D. Arens, T. Fintan Moriarty, R. Richards Geoff, Titanium and steel fracture fixation plates with different surface topographies: Influence on infection rate in a rabbit fracture model, Injury. 47 (2016) 633-639.

[6] C.R.F. Azevedo, Failure analysis of a commercially pure titanium plate for osteosynthesis, Engineering Failure Analysis. 10 (2000) 153-164.

[7] Y. Okazaki, E. Gotoh, Comparison of fatigue strengths of biocompatible Ti-15Zr-4Nb4Ta alloy and other titanium materials, Materials Science and Engineering. 31 (2011) 325-333.

[8] Implants for surgery. Determination of bending strength and stiffness of bone plates (ISO 9585), International Organization for Standardization (1990).

[9] Plastics. Methods for determining the modulus of elasticity in tension, compression and bending. Interstate standard GOST 9550-81, IPK Publishing house of standards (1981).

[10] D.M. Cesarone, J.A. Disegi, Techniques in the Application of ISO 9585 Test Method for Determination of Bone Plate Bending Properties, Clinical and Laboratory Performance Bone Plates, Philadelphia, ASTM, 1994. 